\title{
An unusual case of recurrent cannabis induced flashbacks
}

\begin{abstract}
Introduction: Flashbacks are sudden, involuntary, and vivid memories of past personal experiences. In many cases, these powerful memories are closely linked with traumatic events. ${ }^{1}$ The association of psychedelic drugs such as Lysergic Acid Diethylamide (LSD) or Phencyclidine (PCP) with flashbacks is well documented. ${ }^{2}$ Although the association of Cannabis with flashbacks is well known, such phenomena are not well documented and its pathophysiology still appears elusive. ${ }^{3}$ The nosology of Cannabis induced flashbacks in the DSM- $5^{4}$ describes such phenomenon as "Unspecified Cannabis related disorder" which by definition does not meet the full criteria of any specific Cannabis related disorder. The use of Cannabis is considered illegal under federal law, however according to the 2013 surveys of National Institute of Health (NIH), Cannabis use has increased dramatically over the past decade. Although, about 9.5 percent of Americans reported use of Cannabis, 30 percent of users meet the criteria of Cannabis use disorder. ${ }^{5}$ Cannabis induced flashbacks can be misdiagnosed as symptoms of psychosis. With increasing prevalence of Cannabis use, there is a need to provide mental health professionals with the awareness of this phenomenon. The topic of Cannabis causing flashback is of clinical interest, as well as its prognosis and treatments.
\end{abstract}

Volume 9 Issue 5 - 2018

\author{
Alexander Maksymenko, Kodjovi Kodjo, \\ Adenike Ishola, Oluwole Jegede, Khandaker \\ Taher, Tolulope Olupona, Ayodele Jolayemi \\ Interfaith Medical Center, USA
}

Correspondence: Kodjovi Kodjo, Interfaith Medical Center, 1545 Atlantic Ave, Brooklyn, NY I I 2 13, USA, Tel 7202173470, Email kdkodjovi@gmail.com

Received: August 18, 2018 | Published: September 06, 2018

\section{Case summary}

We report the case of a 35-year- old African American woman with a past medical history of HIV on HAART and history of two admissions for Cannabis induced psychosis. The patient was brought to the Emergency Department by EMS activated by her husband for a psychiatric evaluation after sudden uncontrollable agitation on seeing her husband. She reported she found the normally pleasant perfume of her husband became pungent. The pungent smell was associated with unpleasant past memories. She only recalled preceding event was Cannabis use prior to his arrival home. The triggered memories were associated with a funeral parlor of her 2-year-old sister. The patient stated that she was just 8 years old at that time and had witnessed the death of her sister. She endorsed smoking "a few blunts" one day before the flashbacks started. She described and confirmed an occurrence of similar episodes in the past after marijuana use. She admitted to use Cannabis regularly. On admission her CBC, CMP were in normal limits, ECG was normal and her quick toxicology screen did not reveal any substance. The patient's symptoms responded very well to a trial of Risperidone $1 \mathrm{mg}$ per oral twice a day. She was discharged with aftercare follow-up and admitted to the long term rehabilitation program.

\section{Discussion}

One of the described effects of Cannabis use is the flashback phenomena. Keeler et al., ${ }^{6}$ first reported the Cannabis flashback phenomenon, which consists of re-experiencing the various perceptual and cognitive effects of the drug at a much later date even when no longer under its influence. Thomas ${ }^{7}$ has suggested that 'Flashbacks' or the subsequent partial re-experience of symptoms when drug-free are rarely reported after cannabis use. Although the pharmacokinetics of cannabinoids puts in doubt the existence of drug-free flashback reactions, it was indicated that such experiences may be the result of a continuous or intermittent release of psychoactive component from adipose tissues where they are stored during periods of active usage. ${ }^{8}$ The individual usually re-experiences a visual hallucination or other perceptual disturbance triggered by a familiar smell that can trigger significant memories like in our index case. This was described by Grinspoon \& Bakalaar" as "a transitory recurrence of emotions and perceptions originally experienced while under the influence of a psychedelic drug". There are only a few case reports of Cannabis induced flashbacks. ${ }^{8}$ Weil ${ }^{10}$ however describes eight patients who complained of "recurrence of hallucinogenic symptomatology ('flashbacks')" while intoxicated with Cannabis. Further studies are needed to supplement current research data available regarding the prevalence, prognosis and treatment of Cannabis induced flashbacks. This case illustrates the clinical presentation of Cannabis use which might have triggered flashbacks in a young African American woman.

\section{Acknowledgements}

None.

\section{Conflict of interest}

The author declares that there is no conflict of interest.

\section{References}

1. Brewin CR. Re-experiencing traumatic events in PTSD: new avenues in research on intrusive memories and flashbacks. Eur J Psychotraumatol. 2015;6:27180.

2. Nichols DE. Hallucinogens. Pharmacol Ther. 2004;101(2):131-181.

3. Gaillard M, Borruat FX. Persisting visual hallucinations and illusions in previously drug-addicted patients. Klin Monbl Augenheilkd. 2003;220(3):176-178.

4. American Psychiatric Association. Diagnostic and statistical manual of mental disorders: DSM-V. Washington, DC: American Psychiatric Association; 2000.

5. National Institute of Health (NIH); 2015.

6. Keeler MH, Reifler CB, Liptzin MB. Spontaneous recurrence of marijuana effects. American Journal of Psychiatry. 1968;125:384-386.

7. Thomas H. Psychiatric symptoms in cannabis users. British Journal of Psychiatry. 1993;163(2):141-149. 
8. Basu D, Malhotra A, Varma VK. Cannabis Related Psychiatric Syndromes: A Selective Review. Indian J Psychiatry. 1994;36(3):121-128.

9. Grinspoon L, Bakalar JB. The use of cannabis as a mood stabilizer in bipolar disorder: anecdotal evidence and the need for clinical research. $J$ Psychoactive Drugs. 1998;30(2):171-177.
10. Weil AT. Adverse reactions to marijuana: classification and suggested treatment. N Engl J Med. 1970;282:997-1000. 